\title{
SYNTHESIS AND CHARACTERIZATIONS OF Ag, Cu AND AgCu METALLIC NANOPARTICLES STABILIZED BY DIVALENT SULFUR LIGANDS
}

\author{
YASNA LEÓN ${ }^{*}$, IVÁN BRITO², GALO CÁRDENAS ${ }^{3}$, OLIVIA GODOY \\ 'Departamento de Ciencias Básicas, Universidad Santo Tomás, Arturo Prat \#801, Antofagasta, Chile. \\ ${ }^{2}$ Departamento de Química, Facultad de Ciencias Básicas, Universidad Antofagasta, Casilla 170, Antofagasta, Chile. \\ ${ }^{3}$ Departamento de Polímeros, Laboratorio de átomos metálicos, Facultad de Ciencias Químicas, Universidad de Concepción, Casilla 160-C, \\ Concepción, Chile. \\ (Received 16 April 2008 - Accepted 3 October 2008)
}

\begin{abstract}
The synthesis of $\mathrm{Ag}, \mathrm{Cu}$ and $\mathrm{Ag}-\mathrm{Cu}$ nanoparticles with divalent disulfur ligand by the Brust method were obtained. The metals were reduced by sodium borohydride and stabilized with 2,2'-dithioethanol (L1), N,N'-dithiophtalimide (L2) and triphenylmethanesulfenamide (L3).

The nanoparticles were characterized by TEM, EDX, electron diffraction and FTIR. The stability of the colloids at room temperature was also measured. We can observe a high stability for the colloids dispersion with L3 ligand (>1 week by AgCu-L3, Ag-L3 and Cu-L3). We found TEM studies show a size distribution between 9.7 and $15.8 \mathrm{~nm}$, depending on the ligand.

Electron diffraction analysis for the metallic nanoparticles shows the presence of $\mathrm{Ag}_{2} \mathrm{~S}, \mathrm{Ag}, \mathrm{CuO}$ and bimetallic compounds such as $\mathrm{CuAgS}$. The active solids were obtained by solvent evaporation from the nanoparticles dispersed to $50{ }^{\circ} \mathrm{C}$. The FT-IR exhibit the presence of the ligand incorporated in the solid.
\end{abstract}

Keywords: Nanoparticles, Sulfenamides, Symmetric disulfide, TEM, divalent sulfur.

\section{INTRODUCTION}

The control at nanometer level of material synthesis has been one of the objectives of material science in the last decades, thanks to the advances of characterization and visualization techniques that allow this control. Likewise, the interest for nanostructure material is important, due to their size reduction up to levels one or two order of magnitude, superiors to the atomic size implies the appearance of new properties, opening up a wide range of possibilities in technology $y^{1-2}$. Thus, metallic nanoparticles, for example, gold and silver, present a series of optical (plasmon resonance), electric (conductivity) and physical (capacity of chemisorbed organic molecules) properties different from the bulk state ${ }^{3-9}$.

The stabilization of metallic nanoparticles can be carried out by means of the use of phosphines, thiols, amines, solvents or carbon monoxide ${ }^{10-13}$. For example, Schmid and coworkers synthesized Au, Pt, Pd and Ni colloids stabilized by phosphines. The phenanthroline ligand and its derivatives, and the octanethiol ligand have been used to prepare Pt and Pd nanoparticles ${ }^{14}$. It has recently been reported that nanoparticles can be stabilized by solvent ${ }^{15-16}$ for example; $\mathrm{Ti}$ and $\mathrm{Ru}$ nanoparticles were synthesized in tetrahydrofuran or thioethers such as steric and electrostatic stabilizers. However, in both cases, it did not carry out the coordination of heteroatom of solvent with the metallic surface.

Thiolates are compounds of divalent sulfur (2+), commonly used to stabilize metallic nanoparticles, and are prepared in general by the reduction of metal salts. One of the most common routes for the synthesis to gold nanoparticles functionalized with thiols is the Brust-Schiffrin method ${ }^{17-18}$. The technique synthetic is a two phase system and thiols are used as ligand that strongly binds to gold due to the soft character of both $\mathrm{Au}$ and $\mathrm{S}^{17}$. The thiols in this reaction are involved in the reduction of gold precursor salts to a $\mathrm{Au}$ (I)thiol polymer ${ }^{19}$. Methods produce a very solid stable in the air and are soluble in a wide range of organic solvents. These properties allow easy manipulation and characterization using variety of techniques such as transmission electron microscopy (TEM) and Fourier transform infrared (FTIR) spectroscopy.

The alkanethiols are used commonly in the synthesis of gold nanoparticles forming a monolayer protective $\mathrm{e}^{20-21}$. Recent years have also experimented an explosive growth in studies focusing on the absorption of thiols onto colloidal particles of silver, copper and platinum ${ }^{22-24}$. Other ligands sulfur-containing are xanthates, disulfides and di trithiols which have also been used to stabilize metal nanoparticle $25-26$.

Sulfenamides are compounds that contain sulfur, which has not been studied as nanoparticles stabilizer. These compounds contain trivalent nitrogen bonded to divalent sulfur. We have reported a series of sulfenamides prepared by the metal-assisted technique ${ }^{27-30}$. These sulfenamides have been of great interest to the chemical community because of their industrial applications, their usefulness as synthetic reagents, and ligands of compound coordination 31-34.

In this work we focused on the characterization of $\mathrm{Ag}, \mathrm{Cu}$ y $\mathrm{AgCu}$ nanoparticles stabilized with disulfides and sulfenamides synthesized by Brust method.

\section{EXPERIMENTS}

\section{Nanoparticles formation}

An aliquot of $20 \mathrm{ml}$ of an aqueous solution of metallic salts $\left(\mathrm{AgNO}_{3}\right.$ or $\left.\mathrm{Cu}\left(\mathrm{NO}_{3}\right)_{2}\right) 0.02 \mathrm{M}$ was transferred to an Erlenmeyer flask. The solution is vigorously stirred; $15 \mathrm{~mL}$ of a $0.07 \mathrm{M}$ solution of $\mathrm{N}(\mathrm{n}-\mathrm{C} 8 \mathrm{H} 17) 4 \mathrm{Br}$ in toluene are added. Stir at least 20 minutes to ensure the full transfer of the metal in the organic phase. This transfer can be followed by visual observation of the disappearance of color (blue $\left.=\mathrm{Cu}\left(\mathrm{NO}_{3}\right)_{2}\right)$ of the aqueous phase and the concurrent appearance of a brown coloring in the organic phase, the organic phase is separated, which will be used in the following stage. The reduction was carried out in glass balls of two necks. $50 \mathrm{~mL}$ of aqueous solution $\mathrm{NaBH}_{4} 0.2$ $\mathrm{M}$ were added. The mixture was stirred for approximately 2 hours to complete reaction. The dark-brown organic phase was separated and then mixed with 2 $\mathrm{mL}$ of L1, L2 or L3 ligand in toluene, while stirring for 1 hour until completing the exchange among $\mathrm{N}\left(\mathrm{n}-\mathrm{C}_{8} \mathrm{H}_{17}\right)_{4} \mathrm{Br}$ with ligand in the particle surface. The organic phase was dried with anhydrous magnesium sulphate. The solid was obtained by removal of solvent.

\section{Transmission electron microscopy (TEM)}

Transmission electron micrographs were obtained with a JEOL JEM 1200 EXII with $4 \AA$ A resolution using copper or nickel grids coated with carbon foil. A drop of the colloid was placed on a 150-mesh copper or nickel grid and allowed to dry. The particle size was determined by optical measurements, the diameters of a specific particle population were measured randomly. The data set was represented in frequency histograms, to which distributions of the Gaussians and normal type were adjusted to obtain the respective measurements.

\section{Electron Diffraction}

Electron Micrographs were obtained on a JEOL JEM 1200 EXII; the micrographs were obtained using $120 \mathrm{kV}, 60 \mathrm{~cm}, \mathrm{~K}: 4.209 \AA$. The calibration was carried out with Au film (Aldrich Chemical 99.99\%) evaporated over a copper grid. The deposition was carried out using an Edwards 5.150 Evaporator.

\section{FT-IR studies}

Infrared spectra were measured by using a FT-IR Nicolet Change 330 spectrophotometer coupled to a PC with Omnis software analysis. Spectra were recorded at a resolution $5 \mathrm{~cm}^{-1}$ and 128 scans were accumulated between 350 and $4000 \mathrm{~cm}^{-1}$. 


\section{RESULTS AND DISCUSSION}

The nanoparticles synthesis was carried out by the method of chemical reduction know as Brust method, where a metallic precursor is dissolved in water and it is extracted with a solution of tetraoctylammonium bromide, $\mathrm{N}$ $\left(\mathrm{n}-\mathrm{C}_{8} \mathrm{H}_{17}\right)_{4} \mathrm{Br}$, in toluene. The function of $\mathrm{N}\left(\mathrm{n}-\mathrm{C}_{8} \mathrm{H}_{17}\right)_{4} \mathrm{Br}$ in the $\mathrm{H}_{2} \mathrm{O}$-Toluene system facilitates the break up of the metallic salt in the organic phase. Once the metallic salt was transferred quantitatively to the organic phase (given by a colour change in the phases), an agent reducer was added allowing the formation of metallic particles in the range of the nanometer.

The $\mathrm{N}\left(\mathrm{n}-\mathrm{C}_{8} \mathrm{H}_{17}\right)_{4} \mathrm{Br}$ compound, apart from being reagent of the transfer phase, allows the stabilization of nanoparticles by coordination, avoiding the nucleation among particles. Because n-octil ammonium is slightly coordinated with the metallic surface, this can be replaced easily with a ligand that forms connections covalent with the passive surface.

Scheme 1 shows the formation of metallic nanoparticles and active powders obtained

\section{Tetraoctylammonium bromide $\left(\mathrm{N}\left(\mathrm{n}-\mathrm{C}_{8} \mathrm{H}_{17}\right)_{4} \mathrm{Br}\right)$ in toluene}

Aqueous $\mathrm{M}$ solution $\left(\mathrm{M}=\mathrm{AgNO}_{3}\right.$ and/or $\left.\mathrm{Cu}\left(\mathrm{NO}_{3}\right)_{2}\right)$
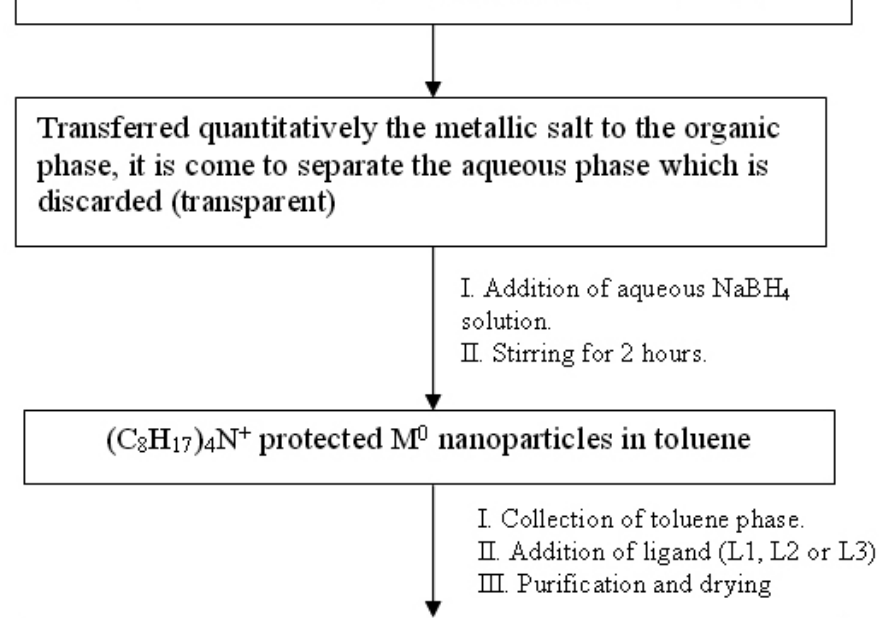

Powder of $\mathrm{M}^{0}$ nanoparticle stabilized with $\mathrm{L} 1, \mathrm{~L} 2$ or $\mathrm{L} 3$

Scheme 1. Schematic diagram of the synthetic procedure to obtain nanoparticles stabilized with L1, L2 or L3 ligands and active solid.

The colloidal stability is a property which indicates how many times colloids dispersion remains as a solution before coagulation. The coagulation can occur for agglomeration and subsequent coalescence between particles and/or chemical modification of their surface because of contact with reactive atmosphere. The stability of the nanoparticles obtained was measured until particle precipitation at room temperature. We found a variable stability for all dispersion series from direct observation. In this sense, we did not find clear dependence of the stability with respect to size of nanoparticles, sulfurated ligand and/or metals. However we can observe a high stability for the nanoparticles dispersion with L3. Table I summarizes the stability with the different ligands and average particle size obtained by TEM.
Table I. Stability and particle size of $\mathrm{Ag}, \mathrm{Cu}$ and $\mathrm{AgCu}$ with different ligands.

\begin{tabular}{|c|c|c|c|c|c|}
\hline \multirow[b]{2}{*}{ Ligands } & \multirow[b]{2}{*}{ Metals } & \multirow[b]{2}{*}{ Ratio } & \multirow{2}{*}{$\begin{array}{c}\text { Stabi- } \\
\text { lity } \\
\text { (days) }\end{array}$} & \multicolumn{2}{|c|}{ Average } \\
\hline & & & & $\begin{array}{c}\text { Particle } \\
\text { size } \\
(\mathrm{nm})\end{array}$ & $\begin{array}{l}\text { SD } \\
(\mathrm{nm})\end{array}$ \\
\hline \multirow{3}{*}{$\begin{array}{r}\mathrm{HOCH}_{2} \mathrm{CH}_{2} \mathrm{SSCH}_{2} \mathrm{CH}_{2} \mathrm{OH} \\
\text { 2,2'-dithioethanol (L1) }\end{array}$} & $\mathrm{Ag}$ & $1: 0$ & $<7$ & 11.5 & 3.2 \\
\hline & $\mathrm{Cu}$ & $0: 1$ & $<7$ & 12.7 & 4.3 \\
\hline & $\mathrm{AgCu}$ & $1: 1$ & $>7$ & 15.8 & 5.7 \\
\hline \multirow[b]{3}{*}{$\begin{array}{l}\mathrm{N}, \mathrm{N} \text {-dithiophtalimide } \\
\text { (L2) }\end{array}$} & $\mathrm{Ag}$ & $1: 0$ & $>5$ & 9.8 & 3.2 \\
\hline & $\mathrm{Cu}$ & $0: 1$ & $>5$ & 10.5 & 3.8 \\
\hline & $\mathrm{AgCu}$ & $1: 1$ & $<7$ & 10.4 & 3.6 \\
\hline \multirow{3}{*}{$\begin{array}{c}\text { Triphenylmethanesul- } \\
\text { fenamide (L3) }\end{array}$} & $\mathrm{Ag}$ & $1: 0$ & $<7$ & 10.8 & 2.3 \\
\hline & $\mathrm{Cu}$ & $0: 1$ & $>7$ & 9.7 & 2.8 \\
\hline & $\mathrm{AgCu}$ & $1: 1$ & $>7$ & 9.9 & 3.3 \\
\hline
\end{tabular}

The TEM studies of the metallic nanoparticle were obtained at bright and dark fields. The size of the particles is represented in a histogram to calculate the normal deviation (Fig. 1 and 2). We observed that the particles sizes fluctuate between 9.7 and $15.8 \mathrm{~nm}$ for the all series. The micrographs show particles an apparently spherical and comparable in appearance to previously reported from alkanethiol-nanoparticle22. The stadistical studies reveal significant dependence of particle size on the kind of ligand. The growth of the nanoparticles can be inhibited by the interaction between the organic molecules and surface atoms for obtaining isolated particles. In general we observed that to bigger volume of ligand, minor is the particle size. However, this does not establish a rule due to a diversity of factors, such a bulky and the functional groups of the ligands.
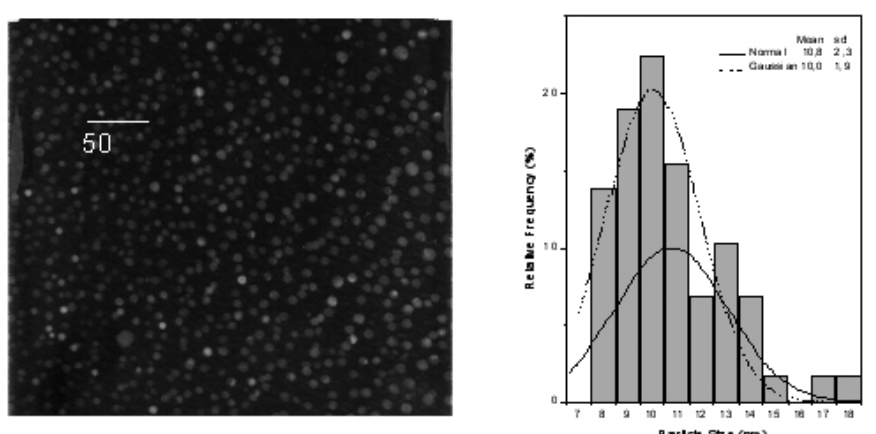

Fig. 1 Electron Micrograph (100 K) in dark field and histogram of Ag-L3 

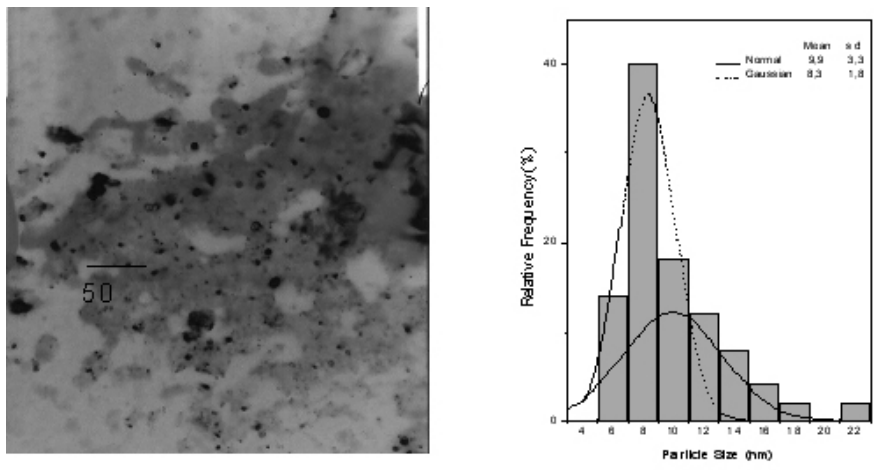
L3.

Fig. 2 Electron Micrograph $(100 \mathrm{~K})$ in bright field and histogram of $\mathrm{AgCu}-$

The EDX analysis shows the presence of $\mathrm{Ag}, \mathrm{Cu}$ and $\mathrm{AgCu}$ metals in the particles, $\mathrm{C}$ and $\mathrm{S}$ of the organic ligand linked to metallic nanoparticles and elements present in the grid (Ni and C)(see Fig. 3)..

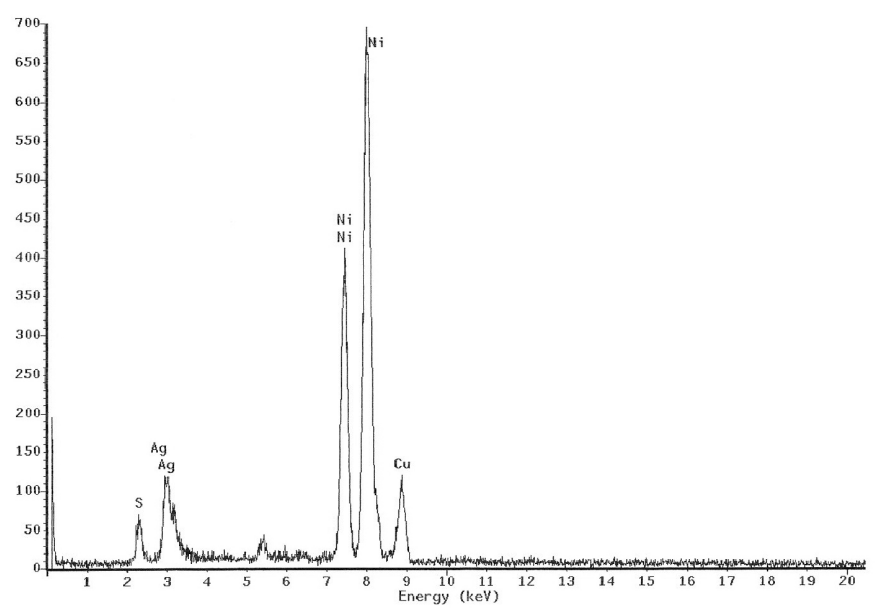

Fig. $3 \mathrm{EDX}$ of $\mathrm{AgCu}-\mathrm{L} 3$

Electron diffraction analysis of $\mathrm{AgCu}-\mathrm{L} 2$ shows the presence of a mixture of alloys (see Fig. 4). The silver and copper alloys identified were $\mathrm{AgCuS}$ and $\mathrm{Ag}_{2} \mathrm{~S}$. The particles are mainly formed by amorphous tiny crystals that give very few diffraction rings. In a similar way, we observed alloys in the other samples, such as: $\mathrm{Cu}_{2} \mathrm{~S}$ and $\mathrm{CuS}$.

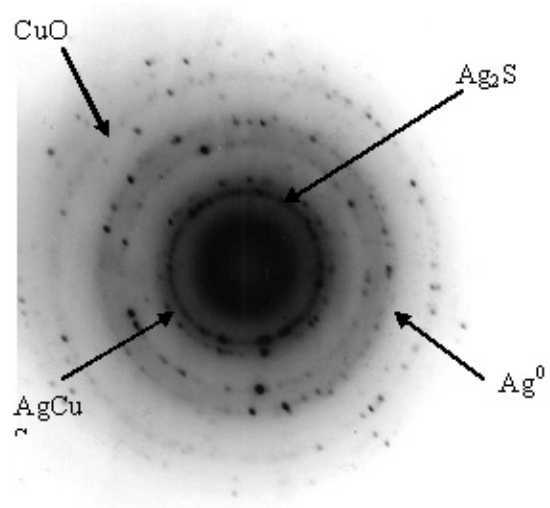

Fig. 4 Electron diffraction of $\mathrm{AgCu}-\mathrm{L} 2$
Table II. Electron diffraction pattern of AgCu-L2 particle

\begin{tabular}{c|cc}
\hline Diameter $(\mathbf{c m})$ & $\mathbf{D}_{\text {hkl }}(\mathbf{A})$ & Phase \\
\hline 1.8734 & 2.247 & $\mathrm{Ag}_{2} \mathrm{~S}(2.246)^{\mathrm{a}}(200)$ \\
2.1772 & 1.933 & $\mathrm{AgCuS}(1.930)^{\mathrm{a}}(004)$ \\
3.595 & 1.170 & $\mathrm{Ag}(1.179)^{\mathrm{a}}(222)$ \\
\hline $\mathbf{4 . 8 1 0 2}$ & 0.875 & $\mathrm{Cu}_{2} \mathrm{O}(0.876)^{\mathrm{a}}(422)$ \\
\hline
\end{tabular}

${ }^{a}$ Data obtained from literature ${ }^{35}$

The FT-IR spectrum of $\mathrm{Ag}, \mathrm{Cu}$ and $\mathrm{AgCu}$ obtained for each one of the solids reveals that there is a coordination of the ligand in the solids. Figure 5 shows the infrared spectrum of $\mathrm{Cu}-\mathrm{L} 1$. The spectra in the active solid shows that they are the same as in the pure ligand but with lower intensity due to the low amount of ligand coordinated in the solids. Table 3 summarizes more relevant frequency of L1, L2 and L3 ligands in the solids.

The FTIR analysis of the solids shows a carbonyl group at $1638 \mathrm{~cm}-1$ for L1 ligand. This is probably due to the interaction of the ligand with the metal surfaces, producing a charge delocalization in the double bond and behaves as a pseudo double bond between the $\mathrm{C}$ and $\mathrm{O}$. It is observed clearly due to the $\mathrm{C}-\mathrm{O}$ stretching around $1111 \mathrm{~cm}^{-1}$, confirming the above observation. On the other hand, the ligands L2 exhibit a large shift of the carbonyl band of 1731 $\mathrm{cm}^{-1}$ from pure ligand to $1637 \mathrm{~cm}^{-1}$ for coordinated ligand. This information is corroborated by the C-O stretching around $1119 \mathrm{~cm}-1$, indicating that the coordination of ligand with the metallic surface is through the oxygen atoms of the carbonyl group. The stabilization of the particles with both ligands (L1 and L2) it is not via S atom, because the frequency of the S-S bonds is not altered with respect to non-coordinated L2. Finally, in the case of L3 ligand, the stabilization of metals is through the sulfur atom, is confirmed due to the disappearance of the band at $931 \mathrm{~cm}^{-1}$ assigned to S-N bond, which indicates the rupture of this. This study is supported by the EDX spectra, in which only sulfur appears.

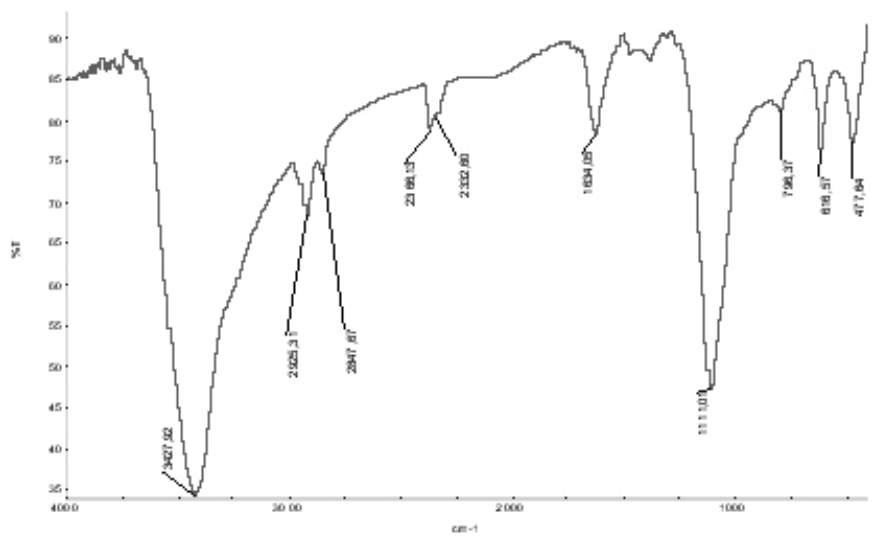

Fig 5. FTIR spectrum of $\mathrm{Cu}-\mathrm{L} 1$ 
Table III. FTIR bands of the metallic films.

\begin{tabular}{|c|c|c|c|}
\hline \multirow{2}{*}{ Ligand } & \multicolumn{2}{|c|}{$v\left(\mathrm{~cm}^{-1}\right)$} & \multirow{2}{*}{ Assignment } \\
\hline & Free Ligand & Active Solids & \\
\hline L1 & $\begin{array}{l}3417 \text { symmetric stretching } \\
2978 \text { asymmetric stretching } \\
-1111 \text { asymmetric stretching } \\
612 \text { stretching } \\
516 \text { stretching }\end{array}$ & $\begin{array}{l}3427 \text { symmetric stretching } \\
2925 \text { asymmetric stretching } \\
1634 \text { symmetric stretching } 1111 \text { asymmetric } \\
\text { stretching } \\
616 \text { stretching } \\
477 \quad \text { stretching }\end{array}$ & $\begin{array}{l}\mathrm{O}-\mathrm{H} \\
\mathrm{C}-\mathrm{H} \\
\mathrm{C}=\mathrm{O} \\
\mathrm{C}-\mathrm{O} \\
\mathrm{C}-\mathrm{S} \\
\mathrm{S}-\mathrm{S}\end{array}$ \\
\hline L2 & $\begin{array}{l}-1740 \text { symmetric stretching } \\
-861 \text { stretching } \\
522 \text { stretching }\end{array}$ & $\begin{array}{l}3423 \text { symmetric stretching } \\
2921 \text { asymmetric stretching } \\
1637 \text { symmetric stretching } \\
1119 \text { asymmetric stretching } \\
861 \quad \text { stretching } \\
498 \quad \text { stretching }\end{array}$ & $\begin{array}{l}\mathrm{O}-\mathrm{H} \\
\mathrm{C}-\mathrm{H} \\
\mathrm{C}=\mathrm{O} \\
\mathrm{C}-\mathrm{O} \\
\mathrm{C}-\mathrm{N} \\
\mathrm{S}-\mathrm{S}\end{array}$ \\
\hline L3 & $\begin{array}{l}3025 \text { symmetric stretching } \\
1604 \text { symmetric stretching } \\
624 \text { stretching } \\
902 \text { stretching }\end{array}$ & $\begin{array}{l}3427 \text { symmetric stretching } \\
3080 \text { symmetric stretching } \\
1625 \text { symmetric stretching } \\
616 \text { stretching }\end{array}$ & $\begin{array}{l}\text { O-H } \\
\text { Aromatic C-H } \\
\text { C=C } \\
\text { C-S } \\
\text { S-N }\end{array}$ \\
\hline
\end{tabular}

\section{CONCLUSIONS}

We have synthesized and characterized metallic nanoparticles stabilized by divalent sulfur ligand. The study of the micrograph revealed a particles size with an average diameter 9 to $15 \mathrm{~nm}$. The EDX spectra corroborate the union between the nanoparticles and ligands.

Electron diffraction shows the presence of $\mathrm{Ag}_{2} \mathrm{~S}, \mathrm{Ag}, \mathrm{CuO}$ and bimetallic compounds such as $\mathrm{CuAgS}$. Presence of silver oxide is not observed. The FTIR spectra show the incorporated ligands in the solids. It was determined that the stabilization of the metallic particles with the oxygenated ligands is through the formation of a pseudo double bond between the carbon-oxygen and not through the sulphur atoms for L1 and L2 ligand. However, in the case of the sulfenamide L3, the stabilization is through sulfur atoms.

\section{ACKNOWLEDGEMENTS}

The authors would like to thank the financial support of Grant INV 56/07 Universidad Santo Tomás, Dirección de Investigación, Universidad de Concepción and Inorganic Laboratories from Departamento de Química, Universidad de Antofagasta.

\section{REFERENCES}

1. G. Schmid, Chem. Rev, 92, 1709, (1992).

2. L. N. Lewis, Chem. Rev, 93, 2693, (1993).

3. A. Roucoux, J. Schulz, H. Patin, Chem. Rev, 102, 3757, (2002).

4. G. Schmid, J. Chem. Soc. Dalton Trans, 1077, (1992).

5. A. Frenkel, C. Hill, R. Nuzzo, J. Phys. Chem B, 105, 12689, (2001).

6. K. Eason, et al, Polyhedron, 13, 1197, (1994).

7. K. Liu, K. Nagodawithana, P. Searson, Phys. Rev B, 51, 7381, (1995)

8. A. Robinson, Science, 194, 1150, (1976).

9. B. Gates, Chem. Rev, 95, 511, (1995).

10. Y. Lin, R.G. Finke, J. Am. Chem.Soc, 116, 8385, (1994).

11. C. Amiens, et al, J. Am. Chem.Soc, 115, 11638, (1993).

12. A. Duteil, G. Schmid, W. Meyer-Zaika, J. Chem.Soc. Chem. Comm, 31, (1995).

13. S. Chen, K. Kimura, J. Phys. Chem B, 105, 5397, (2001).

14. G. Schmid, B. Morun, J. Malm, Angew. Chem. Int. Ed. Engl, 28, 778, (1989).

15. C. Bain, E. Troughton, Y. Tao, J. Evall, G. Whitesides, R. Nuzzo, J. Am. Chem. Soc, 111, 321, (1989).

16. G. Cárdenas, Y. León, Colloid. Polym. Sci., 282, 394, (2004).
17. M. Brust, M. Walter, D. Bethell, D. J. Schiffrin, R. J. Whyman, J.Chem. Soc. Chem. Commun. 801, (1994).

18. M. Brust, J. Fink, D. Bethell, D. J. Schiffrin, C. J. Kiely, J. Chem. Soc. Chem. Commun., 1655, (1995).

19. S. Chen, A. Templeton, R. Murray, Langmuir, 16, 3543, (2000).

20. J. Christopher, L. Estroff, J. Kriebel, R. Nuzzo, G. Whitesides, Chem. Rev, 105, 1103, (2005)

21. M. Daniel, D. Astruc, Chem. Rev, 104, 293, (2004).

22. G. Schon, U. Simon, Colloid Polym. Sci., 273, 101, (1995).

23. A. Dorn, E. Katz, I. Willner, Langmuir, 11, 1313, (1995).

24. A.E. Hanna, M. Tinkman, Phys. Rev. B, 44, 5919, (1991).

25. L. Porter, S. Westcott, M. Graupe, N. Hals, T. Lee, Langmuir, 14, 7378, (1998).

26. T. Yonezawa, K. Yasui, N. Kimizuka, Langmuir, 17, 271, (2001).

27. I. Brito, Y. León, M. Arias, et al, Bol. Soc. Chil. Quim, 47, 159, (2002).

28. I. Brito, C. Díaz, G. Gonzalez, et al, Bol. Soc. Chil. Quim, 44, 459, (1999).

29. I. Brito, Y. León, A. Restovic, et al, J. Chil. Chem. Soc, 48, 51, (2003).

30. I. Brito, M. López-Rodriguez, D. Vargas, Y. León, Acta. Cryst. Sec. E, E62, 0914, (2006).

31. a) L. Craine, M. Raban, Chem. Rev., 89, 689, (1989). b) M. Raban, D. Post, Tetrahedron, 40, 2245, (1989).

32. W. Im, J. Sih, D. Blakeman, J. MacGrath, J. Biol. Chem., 260, 4591, (1985).

33. G. Rackur, M. Bickel, H. Fehlhabver, A. Herling, B. Hitzer, H. Lang, M. Rösner, R. Weger, Biochem. Biophys. Res. Commun, 128, 477, (1985).

34. a) P. Lindberg, P. Nardberg, T. Alminger, A. Bänström, B. Wallmarck, $J$. Med. Chem., 29, 1237, (1986).

35. Powder Diffraction File, Inorganic Phases, JCPDS 1997, International Centre for Diffraction data, Pennsylvania, USA. 